\title{
Use of ICS/LABA on Asthma Exacerbation Risk in Patients Within a Medical Group
}

\author{
Richard H. Stanford, PharmD, MS; Saurabh Nagar, MS; Xiwu Lin, PhD;
} and Richard D. O'Connor, MD

\begin{abstract}
BACKGROUND: Asthma medication ratio (AMR) $\geq 0.5$ has been shown to predict asthma exacerbations. This study explores the impact of increasing or decreasing inhaled corticosteroid/long-acting beta-agonist (ICS/LABA) use over a 7-year period on achieving an AMR of $\geq 0.5$.

OBJECTIVES: To (a) assess the impact of increasing use of ICS/LABAs on changes in a modified AMR (mAMR) and (b) examine asthma risk over time as measured by an mAMR over a 7-year period, adjusting for differences in baseline characteristics.
\end{abstract}

METHODS: This is a retrospective, observational study using pharmacy and medical claims from a medical group from January 1, 2003, to December 31,2010 . All patients with $\geq 1$ asthma diagnosis (ICD-9-CM, 493.xx) with $\geq 1$ inhaled asthma medication dispensed in each year of eligibility were included. The mAMR = total ICS controllers dispensed/(total ICS controllers dispensed + albuterol dispensed). The proportion of ICS/LABA use was determined as the number of ICS/LABA canisters dispensed/(total of ICS/LABA+ICS dispensed). Generalized linear mixed models were used to assess the effect of incremental change in ICS/LABA use on mAMR over 7 years, adjusting for differences in resource utilization, time, and asthma medication use.

RESULTS: Nine hundred ninety patients (mean age $[ \pm$ SD] 34.7 years [ \pm 18.2$], 61.7 \%$ female) met all criteria. Overall, mean mAMR increased over time, while mean albuterol use decreased over time. Adjusting for covariates, we found that a $10 \%$ increase in ICS/LABA use was associated with a $9 \%$ increase (adjusted $0 \mathrm{R}=1.09,95 \% \mathrm{Cl}=1.06-1.12$ ) in the likelihood of achieving an $\mathrm{mAMR} \geq 0.5$, while a $50 \%$ increase in ICS/LABA use was associated with a $53 \%$ increase $(0 \mathrm{R}=1.53,95 \% \mathrm{Cl}=1.31-1.80)$ in the likelihood of achieving an $m A M R \geq 0.5$.

CONCLUSIONS: Increase in ICS/LABA use over time in a population of asthma patients was significantly associated with a higher likelihood of achieving an $m A M R \geq 0.5$.

J Manag Care Spec Pharm. 2015;21(11):1014-19

Copyright $\odot 2015$, Academy of Managed Care Pharmacy. All rights reserved.

\section{What is already known about this subject}

The asthma medication ratio (AMR) is currently being used as a Healthcare Effectiveness Data and Information Set asthma quality measure endorsed by the National Committee for Quality Assurance.

The AMR value of $\geq 0.5$ has been associated with lower risk of subsequent asthma-related exacerbations. Low adherence rates to inhaled corticosteroid (ICS) use may be related to poorer asthma control. Use of ICS/long-acting beta-agonist (LABA) as a fixed-dose combination to ICS alone has not been associated with changes in AMR over time.

\section{What this study adds}

The data from this analysis support the finding that increased use of an ICS/LABA combination in asthma was associated with a greater likelihood of achieving an AMR of $\geq 0.5$.

Increasing the use of ICS by improving adherence and/or reducing the need for rescue albuterol can increase the AMR

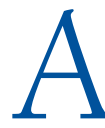
sthma is a chronic inflammatory disorder of the airways characterized by episodic and reversible airflow obstruction, airway hyper-responsiveness, and underlying inflammation. ${ }^{1}$ Common asthma symptoms include wheezing, coughing, and shortness of breath. The majority of asthmatic patients can expect optimal symptom control with correct treatment and avoidance of exposure to environmental allergens and irritants that are known to exacerbate asthma. ${ }^{2}$

In 2010, an estimated 18.8 million adults and 7 million children in the United States had current asthma. ${ }^{2}$ In 2009, there were 2.1 million emergency department visits, 479,300 hospitalizations, and approximately 10.6 million physician office visits for asthma. ${ }^{2,3}$

Previous research has shown that the increased use of inhaled corticosteroids (ICSs) is associated with reduced risk of future asthma exacerbations and mortality. It has been estimated that regular use of ICSs could reduce asthma hospitalizations by as much as $80 \%$, and that the risk of death from asthma decreases by $21 \%$ for each additional ICS canister used. ${ }^{4-7}$ In addition, the overuse of albuterol has been observed to be associated with an increase in the risk of future asthma exacerbations. ${ }^{8,9}$

In 2011, the National Committee of Quality Assurance endorsed a Healthcare Effectiveness Data and Information Set (HEDIS) measure to assess asthma treatment and future asthma exacerbation risk. ${ }^{10}$ This HEDIS measure includes several parts, one being controller adherence, measured using pharmacy claims data, that assesses appropriate treatment. Another measure is the asthma medication ratio (AMR), which assesses future asthma risk. The AMR, which is a ratio of controller use over total asthma medications, has been shown to predict future asthma exacerbations using an AMR threshold of $\geq 0.5$. $^{11,12}$ 


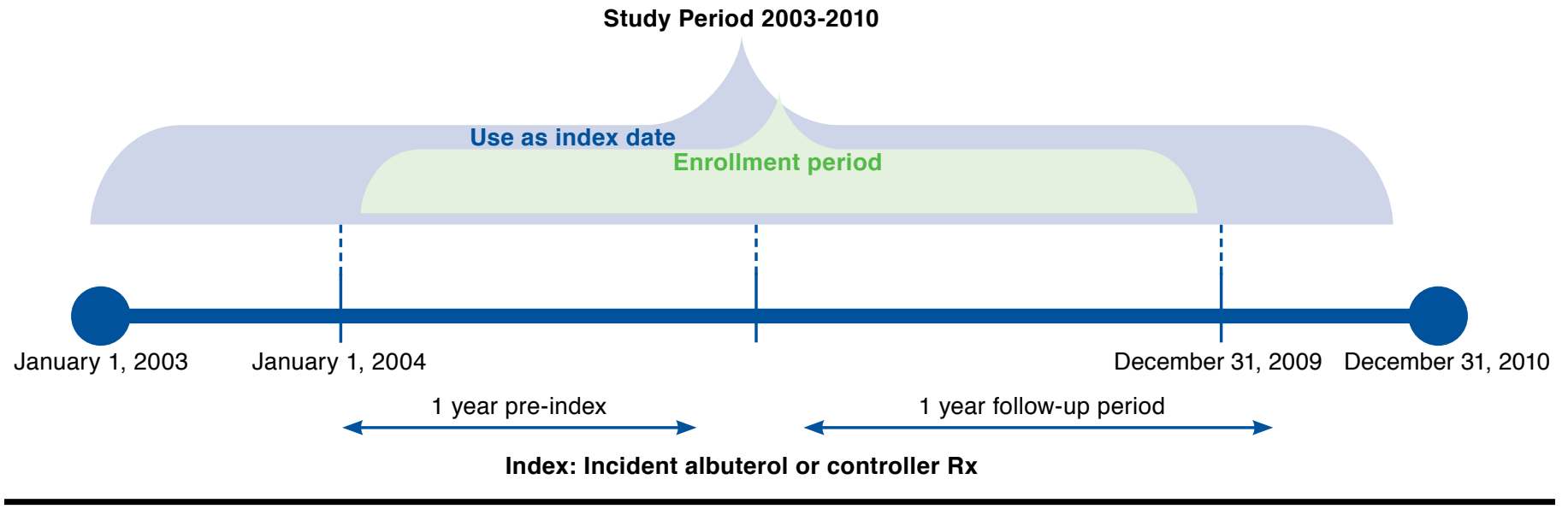

Assessing the effect of ICS therapy, either as monotherapy or as ICS + long-acting beta-agonists (LABAs), on achieving the AMR $\geq 0.5$ threshold may be helpful in making formulary decisions. This study explores the trends of ICS/LABA and ICS monotherapy use over time in a single health plan, specifically assessing the effect of changing ICS/LABA and ICS use over time on the likelihood of achieving an AMR threshold of $\geq 0.5$ (GlaxoSmithKline [GSK] FLT114941).

The objectives of this study were to (a) assess the impact of increasing use of ICS/LABA on changes in a modified AMR (mAMR) and (b) examine asthma risk over time as measured by an mAMR over a 7-year period, adjusting for differences in baseline characteristics.

\section{Methods}

\section{Study Population and Design}

The study was conducted using data from Sharp HealthCare, a not-for-profit, integrated health care system based in San Diego comprising 4 acute-care hospitals, 3 specialty hospitals, 3 skilled nursing facilities, 2 affiliated medical groups, 2,600 physicians, and more than 16,000 employees. As a part of Sharp HealthCare, Sharp Rees-Stealy is San Diego's first multispecialty medical group practice, with 450 physicians, 2,000 staff members, and 21 medical center locations throughout San Diego County. Sharp Rees-Stealy cares for nearly 200,000 patients, primarily through managed care risk contracts.

This was a retrospective observational study using pharmacy and medical administrative claims data from Sharp HealthCare. The study population included adult and pediatric asthma subjects aged $\geq 4$ years who were identified in the database from January 1, 2003, to December 31, 2010. The index date was defined as the first chronologically occurring pharmacy claim for any asthma controller medication or albuterol inhaler during the period of January 1, 2004, to
December 31, 2009. To be included in the study, subjects had to have at least 1 medical claim with a diagnosis of asthma (International Classification of Diseases, Ninth Revision, Clinical Modification [ICD-9-CM], 493.xx) in any field in each year of observation (pre- and post-index); presence of at least 1 asthma controller medication or albuterol inhaler in each year of observation; and continuous health plan eligibility in the 12 months both pre- and post-index. Subjects with $\geq 1$ medical claim for chronic obstructive pulmonary disease (COPD; ICD-9-CM 491.xx, 492.xx, or 496.xx) in any position within the claims in any year of observation were excluded. The study design is depicted in Figure 1.

\section{Study Exposures and Outcomes}

The controller-to-total AMR is calculated as the ratio of 30-day supply/canisters of controller medications used during the measurement year divided by the sum of 30-day supply/canisters of controller medications plus the canisters of inhaled short-acting beta-agonists used during the measurement year. Controller medications include leukotriene receptor antagonists (LTRAs), ICSs, ICS plus LABAs fixed-dose combination inhalers, and methyl xanthenes.

The ratio of $\geq 0.5$ for the AMR is recommended as the cutoff in assessing asthma risk in a population and is associated with a reduction in the risk of asthma-related exacerbation in the following year. ${ }^{11,12}$ In order to assess the effect of changing ICS use over time on the AMR, a modified version of the AMR (mAMR), which used only ICSs in the denominator and numerator, was used in this analysis. Excluding LTRA use in the calculation of the AMR allowed for a more robust analysis of the effect of ICS use, considering LTRAs are used to treat allergic rhinitis, which could confound the association of ICS use and AMR. Values for the mAMR ranged from 0 (no ICS + albuterol) to 1 (ICS + no albuterol). 


\begin{tabular}{l|c|c}
\hline \multicolumn{1}{c|}{ TABLE 1 Subject Attrition } & \\
\hline $\begin{array}{l}\text { Members with } 12 \text { months pre- and post-index } \\
\text { eligibility }\end{array}$ & $\mathrm{N}=23,230$ & $100.0 \%$ \\
\hline Reason for exclusion & $\mathbf{n}^{\mathbf{a}}$ & $\%$ \\
\hline $\begin{array}{l}\text { Asthma patients with no COPD } \\
\text { using controller/albuterol }\end{array}$ & 11,970 & 51.5 \\
\hline $\begin{array}{l}\text { Asthma in pre-index and no } \\
\text { controller in pre-index }\end{array}$ & 5,701 & 24.5 \\
\hline $\begin{array}{l}\text { Asthma diagnosis and controller/albuterol } \\
\text { in all follow-up years }\end{array}$ & 1,072 & 4.6 \\
\hline $\begin{array}{l}\text { Aged } \geq 4 \text { years } \\
\text { Final sample size }\end{array}$ & 990 & 4.3 \\
\hline${ }^{a}$ Not mutually exclusive. \\
COPD = chronic obstructive pulmonary disease.
\end{tabular}

A ratio of ICS/LABA to total ICS use was used to assess changing ICS/LABA and ICS use over time. This ratio was determined annually and semiannually as the number of ICS/ LABA canisters dispensed divided by the sum of ICS/LABA and ICS monotherapy dispensed. In addition, the annual and semiannual albuterol canister use was also determined over the 7-year period.

After calculating the ICS/LABA to the total ICS use ratio and mAMR, we determined the effect of changes in ICS/LABA use over time on the likelihood of achieving an mAMR ratio of $\geq 0.5$, taking into account baseline differences.

\section{Statistical Analysis}

Demographic characteristics and baseline medical conditions were described for the identified asthma cohort using standard summary statistics (means and percentages). To ensure accuracy, the data were reviewed for internal consistency and checked for influential outliers. Generalized linear mixed models (GLMMs) were used to generate predicted mean mAMR, mean ratio of ICS/LABA use, and mean numbers of albuterol canisters over the annual and semiannual periods, adjusting for baseline covariates. The covariates used for the analyses were patient demographic characteristics, overall asthma burden, and resource use in the pre-index period.

Random effects within the patients and the correlations between different time intervals were also handled using GLMMs. The GLMMs were used to assess the relationship between increasing ICS/LABA to ICS market share ratio and the likelihood of achieving an mAMR of $>0.5$. Adjusted odds ratios (ODs) and corresponding 95\% confidence intervals (CIs) were generated, adjusting for covariates and time. Models were run for both the annual and semiannual assessments of ICS/LABA to total ICS ratio and mAMR. All analysis was conducted using SAS software package 9.2 (SAS Institute Inc., Cary, NC). ${ }^{13}$

\begin{tabular}{|c|c|c|}
\hline tudy group & \multicolumn{2}{|c|}{$\mathrm{N}=990$} \\
\hline lean age in years & 34.70 & $(18.20)$ \\
\hline emale, n (\%) & 611 & $(61.70)$ \\
\hline lean number of SABA prescriptions & 0.53 & $(1.85)$ \\
\hline lean number of oral corticosteroid prescriptions & 0.25 & $(0.83)$ \\
\hline lean number of prescriptions & 7.90 & $(13.50)$ \\
\hline lean number of unique prescription drug classes & 3.10 & $(3.60)$ \\
\hline harlson Comorbidity Index, mean score & 0.22 & $(0.92)$ \\
\hline Mean number of unique diagnosis codes & 9.90 & $(12.80)$ \\
\hline \multicolumn{3}{|l|}{ sthma resource utilization } \\
\hline Tumber of asthma-related inpatient visits, n (\%) & 21 & $(2.10)$ \\
\hline lean number of asthma-related inpatient visits & 0.05 & $(0.54)$ \\
\hline $\begin{array}{l}\text { Jumber of asthma-related emergency department } \\
\text { isits, } \mathrm{n}(\%)\end{array}$ & 55 & $(5.60)$ \\
\hline $\begin{array}{l}\text { lean number of asthma-related emergency } \\
\text { epartment visits }\end{array}$ & 0.08 & $(0.42)$ \\
\hline Tumber of asthma-related office visits, n (\%) & 577 & $(58.30)$ \\
\hline lean number of asthma-related office vi & 1.25 & $(1.83)$ \\
\hline
\end{tabular}

a All values in this table are given as mean $( \pm S D)$ unless otherwise indicated. $S A B A=$ short-acting beta-agonist; $S D=$ standard deviation .

\section{Results}

A total of 23,230 subjects were eligible for inclusion into the analysis, with 11,970 of these subjects with asthma and no COPD using at least 1 asthma controller or albuterol during the 7-year period. Attrition of the population when all the inclusion and exclusion criteria were applied to this population is shown in Table 1. A final population of 990 patients met all the inclusion criteria. Mean age of the population was 34.7 years (standard deviation $[S D] \pm 18.20$ ) with $61.7 \%$ female. In addition, mean use of albuterol was $0.53(\mathrm{SD} \pm 1.85)$, and mean use of oral corticosteroids was $0.25(\mathrm{SD} \pm 0.83)$ in the pre-index period. Other baseline characteristics for these patients are presented in Table 2.

Annual and semiannual adjusted mean mAMR, ICS/LABA, and albuterol use to total ICS use ratio over a 7-year period are plotted in Figure 2. Overall, trends over time show that mean annual and semiannual mAMR increased over the 7 years, while the corresponding mean albuterol use decreased over that same time period. The regression analysis predicting the likelihood of achieving an $\mathrm{mAMR}$ of $\geq 0.5$ showed that a $10 \%$ increase in annual or semiannual ICS/LABA to total ICS use ratio was associated with a 9\% increase (adjusted OR $=1.09$, 95\% $\mathrm{CI}=1.06-1.12)$ and an $8 \%$ increase $(\mathrm{OR}=1.08,95 \%$ $\mathrm{CI}=1.05-1.11)$ in the likelihood of achieving an $\mathrm{mAMR}$ of $\geq 0.5$, respectively (Table 3). In addition, a 50\% increase in ICS/LABA use resulted in a 53\% and a $48 \%$ increase in the likelihood of achieving an mAMR of $\geq 0.5$ for the annual and semiannual assessments, respectively. This suggests that an increase in the use of ICS/LABA over time was associated with lower asthma risk in this population of asthma patients. 


\section{FIGURE 2 Adjusted Means over 7 Years $^{a}$}

\section{A. Adjusted Mean mAMR}

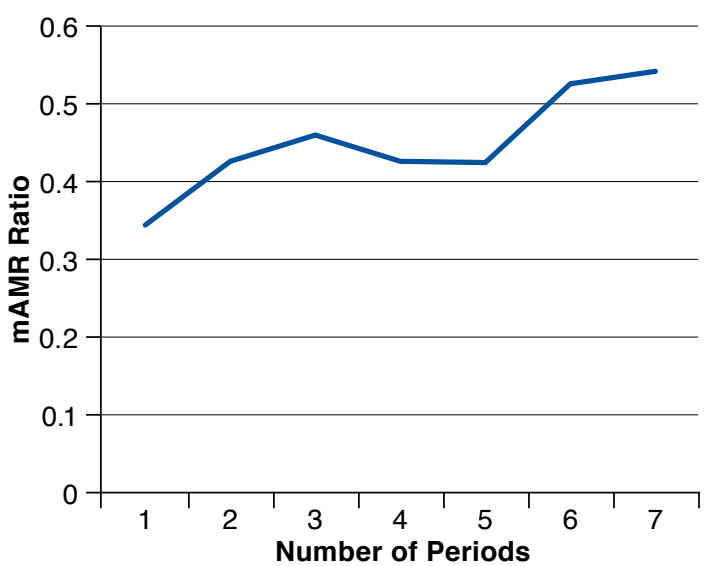

B. Adjusted Mean ICS/LABA Use

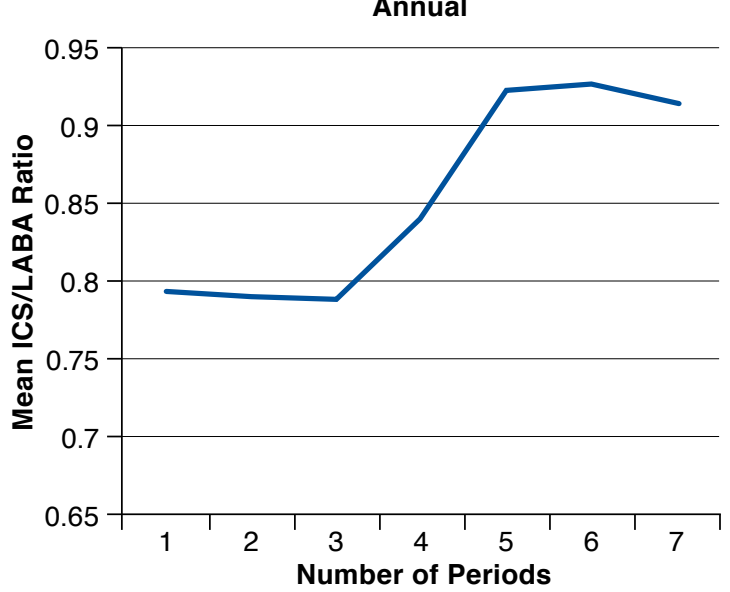

C. Adjusted Mean Albuterol Use

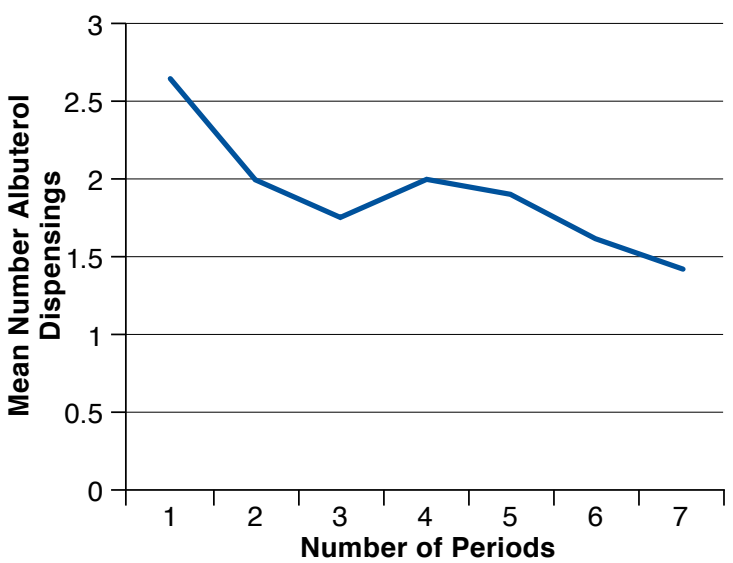

Semiannual

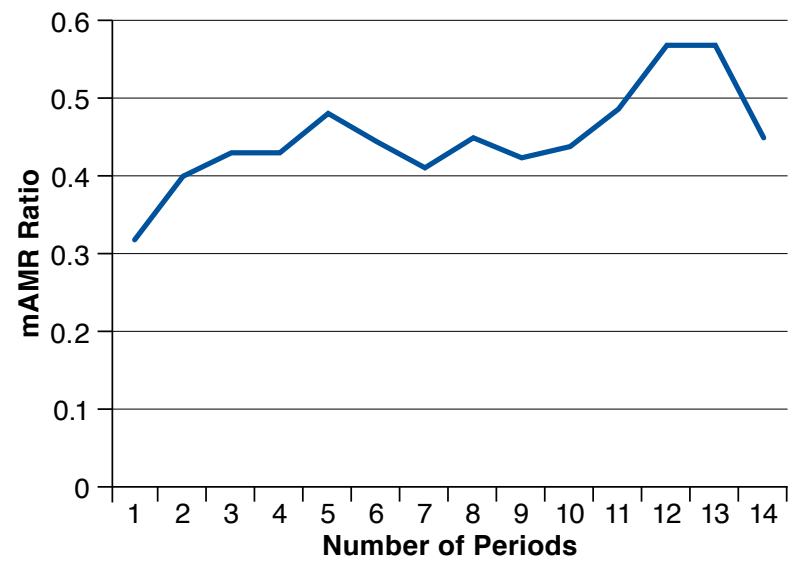

Semiannual

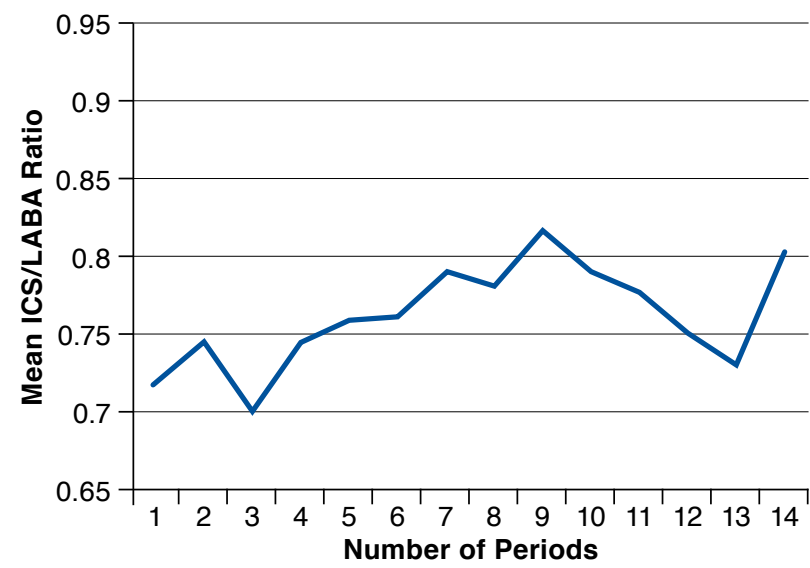

Semiannual

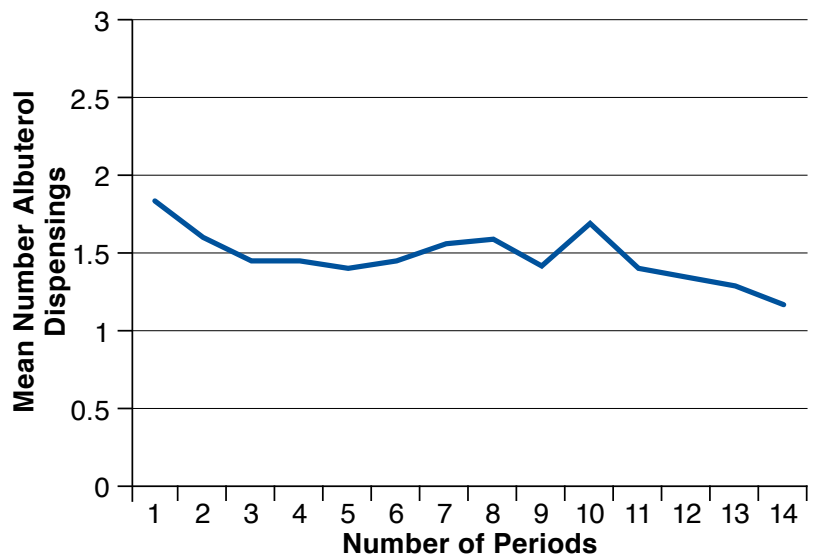

aGeneralized linear mixed model adjusting for index year, age, sex, number of albuterol canisters dispensed, total number of oral corticosteroids dispensed, number of unique drug classes dispensed, total number of medications dispensed, Charlson Comorbidity Index, total number of unique 3-digit diagnoses codes, total number of asthma-related hospital stays, total number of asthma-related office visits, and total number of asthma-related emergency department visits.

ICS = inhaled corticosteroid; $L A B A=$ long-acting beta-agonist; $m A M R=$ modified asthma medication ratio. 


\begin{tabular}{|c|c|c|c|}
\hline TABLE 3 & \multicolumn{3}{|c|}{$\begin{array}{l}\text { Likelihood of Achieving an mAMR } \geq 0.5 \\
\text { for Each } 10 \% \text { Increase in Use of } \\
\text { ICS/LABA }\end{array}$} \\
\hline & & \multicolumn{2}{|c|}{ Adjusted OR $(95 \% \mathrm{CI})^{\mathrm{a}}$} \\
\hline \multicolumn{4}{|c|}{ Annual increase in ICS/LABA } \\
\hline $10 \%$ & & 1.09 & $(1.06-1.12)$ \\
\hline $20 \%$ & & 1.19 & $(1.12-1.26)$ \\
\hline $30 \%$ & & 1.30 & $(1.17-1.41)$ \\
\hline $40 \%$ & & 1.40 & $(1.24-1.60)$ \\
\hline $50 \%$ & & 1.53 & $(1.31-1.80)$ \\
\hline \multicolumn{4}{|c|}{ Semiannual increase in ICS/LABA } \\
\hline $10 \%$ & & 1.08 & $(1.05-1.11)$ \\
\hline $20 \%$ & & 1.17 & $(1.10-1.24)$ \\
\hline $30 \%$ & & 1.26 & $(1.15-1.38)$ \\
\hline $40 \%$ & & 1.37 & $(1.21-1.54)$ \\
\hline $50 \%$ & & 1.48 & $(1.27-1.72)$ \\
\hline \multicolumn{4}{|c|}{$\begin{array}{l}\text { aGeneralized linear mixed model adjusting for index year, age, sex, number of alb- } \\
\text { uterol canisters dispensed, total number of oral corticosteroids dispensed, number } \\
\text { of unique drug classes dispensed, total number of medications dispensed, Charlson } \\
\text { Comorbidity Index, total number of unique } 3 \text {-digit diagnoses codes, total number } \\
\text { of asthma-related hospital stays, total number of asthma-related office visits, and } \\
\text { total number of asthma-related emergency department visits. } \\
C I=\text { confidence interval; ICS=inhaled corticosteroid; } L A B A=\text { long-acting beta- } \\
\text { agonist; mAMR = modified asthma medication ratio; OD=odds ratio. }\end{array}$} \\
\hline
\end{tabular}

\section{Discussion}

This analysis highlights the association of increasing use of ICS/LABA on a new HEDIS quality measure, AMR. The AMR is a measure of asthma exacerbation risk, and this study shows an association of increasing use of ICS/LABA on reducing this risk. This is the first study that has looked at the ratio of ICS/ LABA to total ICS use on asthma exacerbation risk. However, several observational studies have shown the benefits of increasing ICS use on asthma exacerbation risk and mortality. ${ }^{4-6,14}$ Stern et al. (2006) assessed the effect of decreasing use of ICS on future asthma exacerbations. ${ }^{6}$ The authors concluded that every $25 \%$ decrease in ICS use over a year was associated with a $10 \%$ increase in the risk of asthma-related severe exacerbations. ${ }^{6}$ Delea et al. (2008) were able to show that increasing ICS/LABA use had a similar risk reduction on asthma exacerbation. ${ }^{15}$ In addition, Suissa et al. (2000) were able to link increasing ICS use with asthma-related mortality, showing that every canister increase in ICS use in a year was associated with a $21 \%$ reduction in asthma-related mortality. ${ }^{4}$

The use of high levels of albuterol has been associated with an increased risk of asthma-related exacerbations. Schatz et al. (2010), using data from Kaiser Permanente Southern California, associated high levels of albuterol use with poor asthma outcomes. ${ }^{9}$ They concluded that asthma patients receiving more than 4 canisters of albuterol in a year were 24\% more likely to have asthma-related hospital care in the following year. Stanford et al. (2012) showed, after controlling for the use of ICS, that every canister increase in albuterol in a year was associated with an $11 \%$ increase in the risk of an asthmarelated exacerbation in the following year. ${ }^{8}$

The AMR value can be increased several ways: (a) increasing adherence to controllers; (b) decreasing the use of albuterol; and (c) a combination of both. So the effect of increasing ICS/LABA use on a higher likelihood of AMR being $\geq 0.5$ is plausible, considering that observational studies have shown that patients on ICS/LABA as fixed-dosed inhalers tend to refill their controllers more often compared with those on ICS monotherapy. ${ }^{16-18}$ In addition, the use of ICS/LABA has also been shown to reduce the need for albuterol compared with ICS alone. ${ }^{19,20}$ So these observed outcomes together could improve the AMR value in a population of asthmatics.

Whether this effect of ICS/LABA on increasing AMR ultimately reduces future asthma exacerbations remains to be observed. However, a recent network meta-analysis of randomized clinical studies assessing the effect of ICS/LABA in asthma observed a significant $49 \%$ reduction in severe exacerbations compared with low-dose ICS. ${ }^{21}$ This finding is supported by several observational studies. ${ }^{19,20,22,23}$

\section{Limitations}

There are several limitations of the present analysis that should be considered when interpreting this data. Several variables that could affect the observed outcomes were not fully captured in the database, such as lung function information, clinical measures of asthma control, physician samples used by patients, socioeconomic factors, education, and patient employment status. In addition, direct measure of asthma severity was not captured in this dataset.

The methodology and statistical plan for this study that included proxy measures of disease burden and asthma control was used to mitigate the effect of prescribing bias; however, residual confounding may still exist due to the observational nature of this study. In addition, the generalizability outside of this health plan may be limited. However, the use of one health plan allowed for less heterogeneity than would be observed if multiple health plans were used in the analysis. Furthermore, formulary status of medications are not usually known when multiplan datasets are employed; we used only one health plan so the formulary status of ICS/LABA and ICS monotherapy was known and was considered to be equal during the time period of the study.

\section{Conclusions}

The results of this study suggest that the mean mAMR increased over a 7-year time period and that the mean albuterol use decreased over that same time period. The regression analysis adjusting for differences in groups showed that a $10 \%$ increase in percentage of ICS/LABA to total ICS use ratio in the measurement year was associated with a $9 \%$ increased likelihood of the mAMR being $\geq 0.5$. An incremental effect was 
also observed: As the ICS/LABA to total ICS use ratio increased incrementally, so did the likelihood of achieving an mAMR of $\geq 0.5$. This suggests that an increase in percentage of ICS/LABA used may be associated with lower asthma exacerbation risk in a population of asthma patients.

\section{Authors}

RICHARD H. STANFORD, PharmD, MS, is Senior Director, US Value Evidence and Outcomes, GlaxoSmithKline, Research Triangle Park, North Carolina; SAURABH NAGAR, MS, is Research Health Outcomes Scientist, RTI Health Solutions, Research Triangle Park, North Carolina; XIWU LIN, PhD, is Director, Value Evidence and Analytics, GlaxoSmithKline, Upper Providence, Pennsylvania; and RICHARD D. O'CONNOR, MD, is Medical Director, Sharp ReesStealy Medical Group, San Diego, California.

AUTHOR CORRESPONDENCE: Richard H. Stanford, PharmD, MS, Senior Director, US Value Evidence and Outcomes, GlaxoSmithKline, 5 Moore Dr., Research Triangle Park, NC 27709. Tel.: 919.483.3779; Fax: 919.315.5042;

E-mail: richard.h.stanford@gsk.com.

\section{DISCLOSURES}

This study was funded by GlaxoSmithKline (GSK). Stanford and Lin are employees of GSK and own stock in GSK. Nagar was employed by GSK at the time of this study. O'Connor is an employee of Sharp HealthGroup.

Study concept and design were contributed by Stanford, Lin, and Nagar, with assistance from O'Connor. O'Connor collected the data, and Stanford took the lead in data interpretation, assisted by the other authors. The manuscript was written by Stanford, Nagar, and O'Connor, with assistance from Lin, and revised by all the authors equally.

\section{REFERENCES}

1. National Heart, Lung, and Blood Institute. Expert panel report 3: guidelines for the diagnosis and management of asthma. Full report 2007. August 28, 2007. Available at: http://www.nhlbi.nih.gov/files/docs/guidelines/asthgdln.pdf. Accessed October 1, 2015.

2. Moorman JE, Akinbami LJ, Bailey CM, et al. National surveillance of asthma: United States, 2001-2010. Vital Health Stat 3. 2012;(35):1-58.

3. Centers for Disease Control and Prevention. 2012 National Health Interview Survey (NHIS) Data. 2012 lifetime asthma, current asthma, asthma attacks among those with current asthma. Available at: http://www.cdc. gov/asthma/nhis/2012/data.htm. Accessed October 1, 2015.

4. Suissa S, Ernst P, Benayoun S, Baltzan M, Cai B. Low-dose inhaled corticosteroids and the prevention of death from asthma. N Engl J Med. 2000;343(5):332-36.

5. Wells KE, Peterson EL, Ahmedani BK, Williams LK. Real-world effects of once vs greater daily inhaled corticosteroid dosing on medication adherence. Ann Allergy Asthma Immunol. 2013;111(3):216-20.

6. Stern L, Berman J, Lumry W, et al. Medication compliance and disease exacerbation in patients with asthma: a retrospective study of managed care data. Ann Allergy Asthma Immunol. 2006;97(3):402-08.
7. Williams LK, Pladevall M, Xi H, et al. Relationship between adherence to inhaled corticosteroids and poor outcomes among adults with asthma. J Allergy Clin Immunol. 2004;114(6):1288-93.

8. Stanford RH, Shah MB, D'Souza AO, Dhamane AD, Schatz M. Shortacting $\beta$-agonist use and its ability to predict future asthma-related outcomes. Ann Allergy Asthma Immunol. 2012;109(6):403-07.

9. Schatz M, Zeiger RS, Yang SJ, et al. Relationship of asthma control to asthma exacerbations using surrogate markers within a managed care database. Am J Manag Care. 2010;16(5):327-33.

10. National Committee for Quality Assurance. Improving outcomes in asthma: advancing quality using NCQA HEDIS measures. October 25, 2011, webinar. Available at: http://www.ncqa.org/Portals/0/Education/NCQA\%20 Asthma\%20webinar\%200ct\%202011.pdf. Accessed October 1, 2015.

11. Schatz M, Broder M, Chang E, O'Connor R, Luskin A, Solari PG. Asthma quality-of-care measures using administrative data: identifying the optimal denominator. Ann Allergy Asthma Immunol. 2009;102(2):98-102.

12. Schatz M; Stempel D; American College of Allergy, Asthma and Immunology Task Force; American Academy of Allergy, Asthma and Immunology Task Force. Asthma quality-of-care measures using administrative data: relationships to subsequent exacerbations in multiple databases. Ann Allergy Asthma Immunol. 2008;101(3):235-39.

13. SAS Institute Inc. SAS/STAT 9.2 User's Guide. Cary, NC: SAS Institute Inc.; 2008.

14. Stanford RH, Shah MB, D'Souza AO, Schatz M. Predicting asthma outcomes in commercially insured and Medicaid populations? Am J Manag Care. 2013;19(1):60-67.

15. Delea TE, Stanford RH, Hagiwara M, Stempel DA. Association between adherence with fixed dose combination fluticasone propionate/salmeterol on asthma outcomes and costs. Curr Med Res Opin. 2008;24(12):3435-42.

16. Stoloff SW, Stempel DA, Meyer J, Stanford RH, Carranza Rosenzweig JR. Improved refill persistence with fluticasone propionate and salmeterol in a single inhaler compared with other controller therapies. J Allergy Clin Immunol. 2004;113(2):245-51.

17. Stempel DA, Stoloff SW, Carranza Rosenzweig JR, Stanford RH, Ryskina KL, Legorreta AP. Adherence to asthma controller medication regimens. Respir Med. 2005;99(10):1263-67.

18. Bender BG, Pedan A, Varasteh LT. Adherence and persistence with fluticasone propionate/salmeterol combination therapy. J Allergy Clin Immunol. 2006;118(4):899-904

19. Hagiwara M, Delea TE, Stanford RH. Health-care utilization and costs with fluticasone propionate and fluticasone propionate/salmeterol in asthma patients at risk for exacerbations. Allergy Asthma Proc. 2014;35(1):54-62.

20. Delea TE, Hagiwara M, Stempel DA, and Stanford RH. Adding salmeterol to fluticasone propionate or increasing the dose of fluticasone propionate in patients with asthma. Allergy Asthma Proc. 2010;31(3):211-18.

21. Loymans RJ, Gemperli A, Cohen J, et al. Comparative effectiveness of long term drug treatment strategies to prevent asthma exacerbations: network meta-analysis. BMJ. 2014;348:g3009.

22. Stanford RH, Fuhlbrigge A, Riedel A, Rey GG, Stempel DA. An observational study of fixed dose combination fluticasone propionate/salmeterol or fluticasone propionate alone on asthma-related outcomes. Curr Med Res Opin. 2008;24(11):3141-48.

23. Hirst C, Calingaert B, Stanford R, Castellsague J. Use of long-acting beta-agonists and inhaled steroids in asthma: meta-analysis of observational studies. J Asthma. 2010;47(4):439-46. 